\title{
La persecución religiosa y la orden de San Agustín en la Independencia de Filipinas
}

I. LA DEFENSA DEL IDEAL UNIONISTA

\section{a) Las autoridades civiles}

Al tiempo de comenzar este capítulo, debemos advertir que interesa destacar en él, de un modo especial, la actitud mental, el pensamiento y la actitud de las personas que gobernaron Filipinas en la segunda mitad del siglo XIX. Pensamiento y opinión, sobre todo, ante el tema que nos ocupa, y cómo vieron ellos los acontecimientos, cómo reaccionaron y cuáles debieran haber sido sus actuaciones ante el desastre que se avecinaba.

En este sentido, no parece sino que ha existido como un desvío de los historiadores hacia el estudio de la política exterior del pueblo español durante el siglo XIX.

José María Jover nos dice, a este propósito, que no es la pequeñez relativa del Estado español como potencia mundial durante el siglo XIX el único culpable de tal desvío, como quiere Werner Kaegi ${ }^{1}$. (Junto a la endeblez económica, política y militar a que hace referencia nuestra condición de "pequeña potencia) en la Europa ochocentista, es preciso recordar la marginalidad territorial de la Penínsu-

1. W. KAEGI, Historische Meditationen, (Zurich 1942). 23. 
la en relación a los pocos rectores de la alta política; los pueblos mediterráneos serán objeto, en efecto, durante todo el siglo XIX, de una política mundial cuyos hilos conductores se anudan más al Norte; en París y en Londres, en Viena y en Berlín, en San Petesburgo y Washington. Es preciso recordar también la sorprendente pasividad político-internacional de un pueblo fatigado por tres siglos de activa y abrumadora política europea, y privado casi permanentemente, desde 1779 , del indispensable instrumento primario de toda política exterior: un Estado sólidamente establecido, regido por unas minorías identificadas con los intereses permanentes del pueblo de que forman parte) ${ }^{2}$.

Y más adelante nos dirá que la pasividad con que España atraviesa la política mundial del siglo XIX es tan evidente como explicable; explicable por su pobreza esencial, por su crisis política permanente, por su no incorporación a la voluntad industrial. Es evidente que la gran historia universal la hacen otros, y que las decisiones de Madrid se mueven dentro de un condicionamiento muy estrecho establecido allende la Península. Y, sin embargo, si no atendemos exclusivamente a la historia diplomática, sino a las (premisas) de la acción diplomática misma, "los motivos españoles saltan a la vista como factores históricos mundiales de evidente efectividad. El influjo de nuestra guerra de Independencia en el patrón de (guerras nacionales) acuñado por las guerras de Liberación (i8o8-1814); el impacto del liberalismo doceañista español en la Europa de la Restauración y en la conformación política de los Estados iberoamericanos; el influjo y las reacciones provocadas por la presencia de un dominio es. pañol en Cuba y Puerto Rico, hasta 1898 , sobre el naciente sistema americano: he aquí algunos de los motivos aludidos, de que no puede prescindir la historia universal) ${ }^{3}$.

En realidad, la etapa morfológicamente (ochocentista) de nuestra historia nacional, desde el punto de vista de sus conexiones políticas con el exterior, no coincide precisamente con los límites exactos del siglo XIX. Tal etapa viene definida por dos profundos cambios de

2. J. M. JOVER, Caracteres de la política exterior de España en el siglo XIX, (Madrid 1962), 2-3.

3. Ib. 3 . 
estructura territorial: uno inicial (la Emancipación) y otro terminal (la pérdida de Cuba, Puerto Rico y Filipinas).

Avanzando un poco en la historia para referirnos al punto que nos interesa, diremos con el autor citado que el pesimismo constituye el más profundo hecho de psicología colectiva, desde el cual cabe explicar el comportamiento exterior de la España del último cuarto de siglo. El fundamento objetivo de tal pesimismo constituye un hecho tan complejo como discutible. Desde un punto de vista interior, parece exacta la tesis de Ramos Oliveira, que ha llamado la atención acerca de la injusta falta de fe en su propio pueblo, en que se basa la pose pesimista del equipo gobernante durante los años de la Restauración. Pero si colocamos a España en el plano de la política mundial, el pesimismo aparecerá plenamente justificado en razón de las dificultades que acumula una época en la cual España deviene, en relación con el nuevo poder de las grandes potencias del momento, más "pequeña potencia» que lo fuera a mediados de siglo".

La última década del siglo XIX reservaba a los pueblos ibéricos, pues, la más grave crisis internacional padecida desde la Emancipación americana.

Ante la guerra con Estados Unidos, España va a contar con la simpatía de Europa continental; pero con ninguna alianza que aminore la fabulosa desproporción de fuerzas, o que haga imposible una guerra a la cual nos prestamos con escaso sentido de la realidad los españoles. "Obligada España a renunciar su soberanía en el Archipiélago filipino -leemos en la historia de las Relaciones Exteriores de España durante el siglo XIX, de Becker-, los comisionados españoles se limitaron a consignar una protesta, y dejaron a los americanos que fijasen libremente los límites del territorio que cedíamos). Así lo hicieron. El artículo $3 .^{\circ}$ del Tratado de París traza la demarcación correspondiente "quedando tácitamente convenido que continuarian bajo la soberanía de España todos aquellos territorios de los cuales no se había hecho especial mención como cedidos a los Estados Unidos)".

\footnotetext{
4. Ib. 31 .

5. Becker, Historia de las Relaciones Exteriores de España durante el siglo XIX, (Madrid 1950), III, 156.

Estos territorios no eran otros que las islas Marianas (a excepción de la de Guam), las islas Palaos, las Carolinas; y eran también las islas delarchipiélago filipino Sibutú y Cagayán de
} 
Por lo que se refiere a Filipinas, he aquí lo que leemos en uno de los escritores agustinianos: "Teníamos algo grande que purgary el cielo derramó en nuestros párpados soporífero beleño y nos echamos a domir, creyendo soñar prosperidades y grandezas; y he aquí que al despertar nos vemos maltrechos y rotos, nuestras colonias perdidas, mancillado nuestro honor, blanco de las befas, y desprecios de los que nos temblaron un día. ¡Pobre España! A qué extremos de postración y decadencia ha sido arrastrada por las torpezas y desaciertos de sus gobernantes; de aquellos a quienes en mal hora confió la prosperidad de su pueblo y sus grandes destinos en el concierto de las naciones) ${ }^{6}$.

Con estas palabras, tristes, pesimistas, de tono elegíaco y elo. cuencia de honras fúnebres, comenzaba uno de sus capítulos el autor de las "Memorias del cautiverio», P. Graciano Martínez, ilustre prisionero durante dieciocho meses de las insurrectas Filipinas.

Si la historia de los gobernadores generales de Filipinas es gloriosa, llegado el siglo XIX, tendríamos que dar vuelta a la hoja, pues, salvo honrosas excepciones, los gobernadores que envió a aquellas colonias el ministerio de Ultramar dejaron mucho que desear y fueron causantes, en gran parte del desastre nacional. Sin estar del todo conformes con lo que dice el autor de las "Memorias del cautiverio", ni menos con su estilo grandilocuente y de panegírico barato, volvemos a transcribir otro de sus párrafos porque él nos lleva al hilo de nuestro capítulo: "Vibra la pluma al recordar el cuadro histórico de esta agonizante centuria. Desde que el verbo (libertad" resonó..., se vió suplantada por esa peste de liberalismo; desde que se les arrebató a nuestros monarcas las riendas del Estado para hacer que las.llevasen gentes impías dadas en cuerpo y alma a las exigencias de las logias, no hay que preguntar por la historia de España; no tenemos

Joló. "Fugaz imperio - dice Jover- que apenas durará dos años más en manos españolas; el reciente desastre habia venido a acreditar como mal merior la venta con salud. Por iniciativa alemana, interesada en los tres achipiélagos primeramente citados, se entablan negociaciones liamadas a culminar en el Tratado Hispano-Alemán de 30 de junio de 1899: España cede a Alemania las islas Carolinas, las islas Marianas y las Islas Palaos contra el pago de 25 millones de marcos. En cuanto al Tratado Hispano-norteamericano de 7 de noviembre de 1900 , hubo de significar, más que la compra de Sibutú y Cagayán de Joló por los Estados Unidos, el rescate por parte de la última potencia, mediante el pago de cien mil dólares, de la imprecisión con que los plenipotenciarios dictaron la mencionada cláusula tercera; ya que, en la redacción de la misma, los territorios mencionados quedaban técnicamente sin contradicción posible, bajo la soberanía española..."

6. G. MARTINEZ, Memorias del Cautiverio (Manila 1900), I, 4. 
historia o es un montón de ruinas, un río de lágrimas, que aún está pasando cada vez más desbordado y crecido's ?. Porque si los ministros son responsables ante la nación por ministerio de ley, ¿por qué razón no han de ser responsables ante el Gobierno y ante la nación aquellos a quienes se les confía la dirección de los negocios públicos en lejanos países donde ondea la bandera española?

Esto se preguntaba, allá por los años 1896-1897 José María del Castillo y Jiménez, autor de (El Katipunan» o «El Filibusterismo en Filipinas ${ }^{8}$.

A finales del siglo XIX podía observarse cómo el espíritu de la época traía, junto a positivas ventajas, lacras como el favoritismo y el individualismo, en cuyas corrientes vivían y latían ciertos sistemas de gobierno, y de esta suerte, nada tenía de extraño que el desenfreno siguiera a la perturbación, a las injusticias y al desorden de toda clase.

¿Qué ocurría en Filipinas a punto de finalizar el siglo XIX? Más adelante veremos cómo se había despertado entre los naturales un ansia de insurrección y de independencia, capitaneada por el cabecilla del movimiento, $y$, sin duda, el principal y primer intelectual que tuvo, José Rizal.

El gobierno de Madrid, ante el peligro que comenzaba en Filipinas, juzgó necesario implantar en el territorio un sistema de atracción que contuviese a los descontentos. Las reformas contenidas en el régimen municipal, confeccionado por Maura, pedían también para su desarrollo un hombre de las condiciones del general Blanco, el cual venía a sustituir en 1896 al "débil e iluso» Despujol.

Efectivamente, los deseos del Gobierno comenzaron a ponerse en práctica, y las libertades que se otorgaron en virtud de este régimen utilizáronse para afianzar los preámbulos de una soñada independiencia. A este propósito, observa el autor de los "Apuntes históricos de la Provincia Agustiniana del Santísimo Nombre de Jesús de Filipinas): "Las personas sensatas y amantes del orden no pudieron menos de ver con antipatía aquellas reformas y procedimientos

\footnotetext{
7. Ib. 10

8. J. M. del CASTILLO y JIMENEZ, El Katipunan o el Filibusterismo en Filipinas, (Madrid 1897), 5.
} 
de la primera autoridad: eran reformas y procedimientos evidentemente peligrosos para nuestra soberanía).

"Así se dijo, pero las observaciones sinceras de lo que mejor habían estudiado las circunstancias del país cayeron en el vacío. La audacia de los separatistas llegó al extremo de adiestrar casi en público a las futuras huestes de la insurrección. No ignoraban este detalle el conde de Peñaplata ${ }^{9}$ y sus últimos consejeros, y, sin embargo, escucháronse con no disimulada indiferencia aquellos avisos que repetidas veces les dirigieron los verdaderos e indiscutibles patriotas. Esta es la historia; no la tergiversemos por el sólo interés de encubrir nuestro honor), ${ }^{10}$

Las sociedades secretas continuaban sus trabajos a ciencia y paciencia del conde de Peñaplata. Este, sin embargo, empeñábase en dar crédito al núcleo de aduladores que invadían su residencia sin otros fines que colocar en sus ojos la venda de la hipocresía y garantizar los ensayos de exterminio que se fraguaban a la sombra de la ingratitud ". Pero al llegar aquí, justo es que nos detengamos ante dos figuras cumbres españolas que llenaron y dirigieron la política de su tiempo. Nos referimos a Cánovas del Castillo y Antonio Maura los dos tan relacionados con el gobierno de Filipinas como ministro de Ultramar y como jefes del gobierno español en hora punta y difícil para la nación.

Don Antonio Cánovas del Castillo, el ministro de la Restauración, es ya ministro de Ultramar por el año 1865 . El nunca había visto las aguas del Atlántico más que unos días en Cádiz; pero en las Cortes había pronunciado un fogoso discurso contra el abandono de la isla de Santo Domingo y esto era ya bastante para ganarse justamente la cartera en un tiempo en que tantos hombres mediocres se sentaban en el Banco Azul.

Cánovas trata, desde el primer momento, de informarse de la

\footnotetext{
9. Tal era el título nobiliario que poseía D. Ramón Blanco y Erenas.

10. B. MARTINEZ, Apuntes históricos de la Provincia Agustiniana del Santisimo Nombre de Jesús de Filipinas, (Madrid 1909) XLV, 481.

11. Es triste observar esta ceguera de la primera autoridad española en Filipinas, hasta el punto de que, descubierta la insurrección por un religioso agustino, del que más adelante nos hemos de ocupar con detenimiento, P. Mariano Gil, entonces párroco de Tondo, casi llegó a mirársele con menosprecio y sólo porque ponía de relieve los inconcebibles descuidos de la primera autoridad de las islas.
} 
situación de las colonias. Las numerosas respuestas que recibió fueron informándole de la situación y le hicieron ver con clarividencia la necesidad de una reforma a fondo.

Cánovas, siendo jefe de gobierno, no estuvo conforme con la política de mano abierta en Cuba, política que patrocinará Maura. Esta política le hubiera hecho perder muchos elementos de apoyo que le eran necesarios, sobre todo, los económicos, para sobrevivir. Cánovas no estuvo conforme con la política de mano abierta y por eso consiguió hábilmente que los proyectos de Maura los oxidase el tiempo poco a poco y sin escándalo de nadie como no fuera del propio ministro de Ultramar que acabó dimitiendo ${ }^{12}$.

Así se llega al 24 de febrero de 1895 en que estalla el «Grito de Baire", con lo que comenzaba la guerra de Cuba. Sagasta sigue la política de (dejar pasar las cosas». El problema nacional es grave: su gobierno se hunde en el desprestigio y en la impotencia. La perspectiva económica es fatal y se hace preciso, por otra parte, enviar refuerzos militares a Cuba.

Cuba era una urgencia a la que ya no podía volverse la cara. El "Grito de Baire» había transcendido por la Manigua con la rapidez de la pólvora. Máximo Gómez y Maceo estaban de nuevo en la isla prontos a la lucha.

Era preciso actuar y con urgencia. A Cánovas no se le ocurre otra idea que la de someter a la isla. Cánovas seguía decidido a empeñar el último hombre y la última peseta y a poner en la balanza de la contienda la mayor "fuerza física y moral» de España.

Cánovas en esta ocasión - -sigue comentando Comellas- tal vez no acertó a ver cómo aquella gran fuerza moral y física española se hallaría compensada por la larga distancia, por el fanatismo de los insurrectos y, sobre todo, por el apoyo abierto y declarado de Estados Unidos.

Parece obvio decir (a posteriori» que Cánovas se equivocó. Pero cabe pensar que no había ya otra solución que la de la guerra sin cuartel. De hecho, esto se vio claro cuando se trató de aplicar la tesis automática de Sagasta, y es porque, cuando las reformas no se aplican a tiempo, no sirven más que para precipitar la ruptura ${ }^{13}$.

\footnotetext{
12. J. L. COMELLAS, Cánovas, (Madrid 1963), 334

13. J. L. COMELLAS, o.c. 335.
} 
Martínez Campos, el hombre fuerte, se siente pesimista y des. animado una vez que llega a Cuba como Capitán general. La carta que escribe a los tres meses de su llegada a La Habana -25 de julio de 1895 - al presidente del Consejo de Ministros es un auténtico jarro de agua fría. Y "lo admirable es que durante dos años largos - comenta ahora el Marqués de Lema -el ánimo de Cánovas secundado diplomáticamente con aliento por el segundo duque de Tetuán, ministro de Estado, no flaqueara, no obstante la natural decepción que le producían el escaso éxito militar y la oposición en la Península de la prensa, políticos liberales y disidentess) ${ }^{14}$.

Cánovas, en aquel momento tan crítico, consultó a todos los altos mandos a través de su ministro de la guerra, general Azcárraga, antes de decretar la movilización. Después, en enero de 1896, España tenía en Cuba I 13.000 hombres. Pocos días más tarde, era designado para Capitán general de la Isla Don Valeriano Weyler, el hombre que emplearía la política de "mano dura" ante el fracaso de Martínez Campos, contemporizador y que había seguido el camino de la táctica blanda.

Difícil tarea la que se le imponía al nuevo gobernador. Un año antes y siguiendo las iniciativas de Maura todo hubiera sido más sencillo. Ahora era preciso empezar de nuevo y desandar lo andado. Weyler tendría en contra "la opinión" del Viejo Mundo y mucho más, la del Nuevo. Seguramente que Cánovas no supo comprender a tiempo la magnitud de este nuevo peligro: la opinión de Estados Unidos.

Así parece declararlo el conde de Romanones, el cual afirma que la mayor responsabilidad de Cánovas (rradica en no haber descubierto a tiempo los propósitos de Estados Unidos, el no haber aprovechado las benévolas disposiciones del presidente Cleveland cuyo mandato tocaba a su término, ni el espíritu conciliador del secretario Olneys) ${ }^{15}$.

Parece que Cánovas no podía aceptar la mediación de Estados Unidos en los asuntos de Cuba que es lo que pedía la nota Olney.

\footnotetext{
14. MARQUES DE LEMA, Cánovas o el hombre de Estado, (Madrid 1931), 239-40.

15. CONDE DE ROMANONES, Sagasta o el político, (Madrid 1980), 589.
} 
"Para que Cánovas hubiese aceptado — comenta Fernández Almagro- habría tenido que volver a nacer' ${ }^{16}$.

El asunto empeoró más de lo previsto y Cánovas estuvo ahora pensando mucho las cosas antes de decidirse. De hecho, el 6 de febrero de 1897 aparecía en la "Gaceta) un Real Decreto por el que se proponía para Cuba un plan de reforma más amplio aún que el que Maura había propuesto dos años atrás. Al fin, Maura iba a tener razón. Pero ya era tarde.

El nuevo Presidente de Estados Unidos, Mac Kinley, comenzó su gobierno prometiendo defender los intereses americanos allí donde se encontrasen amenazados; pero afirmaba también que su Nación no abrigaba propósitos de agresión contra nadie. Es más, parece que el proyecto de reforma en Cuba parecía complacerle. ¿Qué hubiera ocurrido de no haber caído asesinado Cánovas en este momento? El citado marqués de Lema, gran amigo y seguidor del ilustre político conservador, no duda en afirmar que Cánovas no hubiera entrado en guerra con los Estados Unidos de América. El confiaba en la política como arte de circunstancias, si bien desconfiaba de que España no sabría frenar a tiempo su actitud en las Antillas si los Estados Unidos se decidían a intervenir, como así ocurrió. "Puedo apuntar, sin temor a equivocarme -escribe Lema- que, si todos sus esfuerzos hubiesen fallado, Cánovas habría, en el momento más oportuno, accedido a una inteligencia con los Estados Unidos, pero dejando a salvo la soberanía y, sobre todo, la dignidad de España y el concepto de que aún gozábamos en la opinión internacional»" ${ }^{17}$.

¿'Y qué decir de Maura, gran político, seguramente el más notable de todos los de este momento histórico? Maura está vinculado a Filipinas como ministro que fue de Ultramar en los días más calamitosos que han conocido las Islas. Maura está vinculado al Archipiélago magallánico y su nombre ha sido muy discutido, sobre todo, a raíz de la reforma municipal que trató de implantar en las lejanas colonias de su mando. La reforma municipal que, si aportaba algunas soluciones, sirvió también para fomentar el filibusterismo. La masonería revolucionaria gestionó con sus agasajos y con sus influencias la organización de las antiguas Principalías. Esto llevó a algunos autores 
como a José M. del Castillo, a criticar duramente al ministro de Ultramar hasta llegar a decir que la reforma municipal de Maura es un verdadero engendro; si bien luego nos aclara que no le tuvo que mover alguna ambición torpe "pues el ex-ministro fusionista no es capaz de manchar su conciencia por un mezquino regalo; esto lo saben todos y nadie lo pone en duda. Posible es que le movieran los ecos que a él llegaban de estos mesticillos y traviesos indios que, traidores por naturaleza y el impulso de la sangre heredada, traicionaran sus sentimientos. Porque esto ha debido ser la única causa que produjera tanta desdicha) ${ }^{18}$.

Resulta demasiado simple esta explicación para ser verdadera. El problema es mucho más complejo y más serio que una simple intriga de la masonería.

Tomemos el asunto, desde más atrás y tratemos de juzgar al gran político español con un criterio más objetivo, como el caso lo requiere.

Siendo ministro de Ultramar, 1892, Maura presentó un proyecto de ley de reforma de la administración de la Isla de Cuba, concediendo a los cubanos un régimen que en algunos aspectos se aproximaba al autónomo. Maura - nos dice José Luis Comellas- era un hombre nuevo, explosivo que, cosa inaudita en los anales parlamentarios españoles, no se levantaba a hablar más que para decir cosas importantes ${ }^{19}$.

Ante el desastre nacional y después de la pérdida de las colonias, la decepción fue tanta, que no se explicaría sin la gran ilusión de la víspera. Silvela se mostraba pesimista — nos dice Pabón- en gran manera y atacaba duramente al canovismo. Estaba desilusionado. "Hoy por hoy, exclama en las Cortes, el país no quiere escuadra, no quiere ejército, no quiere Instrucción Pública. Tenéis delante a un hombre que ha perdido la fe, que ha perdido la esperanza ${ }^{20}$.

En cambio, Maura se mostraba más optimista, aunque tuviera más motivos que nadie para disculparse, ya que no se le hizo gran caso cuando ocupó la cartera de Ministro de Ultramar. En el Parlamento

18. J. M. del CASTILLO, El Katipunan, (Madrid 1897), 55-58.

19. J. L. COMELLAS, Cánovas, 330.

20. J. PABON, Cambó, (Barcelona 1952), 46. 
y frente a los partidos, confesó: "La opinión a que yo atiendo es la de las gentes que están en sus casas, en su taller, que hablan en los caminos, en las tertulias, en los salones y en las tabernas... Al pueblo español, al desdichado pueblo español especialmente herido en sus fibras más delicadas y más santas por la adversidad más ruda ${ }^{27}$.

Pero aquel optimismo inicial se trocó bien pronto por un pesimismo hondo y duradero y más complejos también sus motivos. El juego inicial entre optimismo y realidad pudo ajustarse a la estimación de la verdad del sistema y de la bondad del pueblo. "En Maura se cumplió - dice Pabón- con la propia estimación, la de los hombres públicos, y la del Rey) ${ }^{22}$.

Pero Maura será siempre y por encima de todo un gran político y un gran hombre. "Maura hizo de sus decisiones cuestión de conciencia y razón de continuidad por brusca que pareciera alguna vez su actitud. La línea esencial de su pensamiento y de su conducta no sufrió dislocación que hiciese quebrar el prestigio que en el orden de las virtudes personales nadie pudo autorizadamente negar') ${ }^{23}$ La ética de su vida privada, profesional y politica fue proclamada a veces hasta por sus mismos enemigos, y ante ella se estrellaron ataques diversos como los de Macías del Real, Sol, Ortega y Sánchez To$\mathrm{Ca}^{24}$.

Hasta tal punto estuvo Maura en el candelero de la fama y de la política española, que en las Cortes de I9I 4 Lerrux se dejó decir que la vida pública de aquellos años giraba en torno a una personalidad: (con Maura, contra Maura, o alrededor de Maura» ${ }^{25}$.

$Y$ en efecto la relación con Maura es punto de referencia para situar y extender a cualquier político de su tiempo, como Moret, o Canalejas, Dato o Romanones, Sánchez Guerra o Cierva. Lo mismo que el político catalán Cambó, el cual no solo no escapa de la regla general, sino que no se explicaría por entero sin el caso Maura. Pues es evidente, que, desde 1909 a I923, Maura constituyó un caso que no halla semejante en la política española contemporánea y menos aún fuera de ella.

\footnotetext{
21. Ib. 46 .

22. Ib. 46 .

23. M. Fernandez Almagro, Prólogo al libro Maura, de Sevilla Andrés, 10.

24. J. PABON, Camb6, 65.

25. J. PABON, Camb6, 62.
} 
Para el citado Pabón, lo más importante en la gran crisis de I909 - caída de Maura y hechos consiguientes-, no fue la victoria de la izquierda, ni la mudanza de la mecánica política; sino la proyección de un Maura nuevo o distinto: El Maura del Maurismo.

El hombre cuyo apartamiento se inicia entonces, no es un ánimo acabado como el Silvela de 1903; es un espíritu vivo y vigoroso, con una gran herida abierta. De este modo se explica que un maurista destacado e historiador insigne, Ballesteros Beretta, escribiera del movimiento político derivado de tal actitud: (se gestaba el maurismo en su táctica combativa sin lograr una diferencia doctrinal. Quizá si hubiese sıguido el rumbo estridente y antidinástico, lograse el matiz que no encontraba) ${ }^{26}$.

Para Maura, en aquella coyuntura histórica que siguió al desastre colonial, se trataba de una Epaña que bostezaba ausente y perezosa, necesitaba de una agitación que la incorporase a los negocios públicos; la España vital que habría de integrarse a la España oficial. Cuando la revolución de 1909, Maura no perdió la cabeza cediendo a impulsos de inconstitucionalidad y prefirió ser decapitado en el Banco Azul si la oposición de Su Majestad -en el clásico lenguaje parlamentario- se decidía a ejecutarle ${ }^{27}$. Maura en aquella hora mostrose más severo que nunca, aunque luego en su casa y delante de su primogénito llorara sin consuelo ${ }^{28}$.

Se limitó a decir, al tiempo de salir de palacio: "ya hay vacante. Nueve ministros, nueve vacantes. He puesto la dimensión de todo el gobierno en manos del Rey, razonándola con esta nota que entrego a ustedes). Y en aquella hora, dolorosa para él y para España Maura se vería defendido contra las acusaciones de su sustituto Moret nada menos que por Cambó, el más prestigioso político catalán de aquellos días ${ }^{29}$.

Este fue Maura y así creemos que debe ser enjuiciada su actua-

\footnotetext{
26. A. Ballesteros berettA, Historia de España, VIII, Madrid 1936.

27. M. FERNANDEZ ALMAGRO, Alfonso XIII, (Barcelona 1933), 151.

28. G. MAURA Y GAMAZO-M. FERNANDEZ ALMAGRO, Porqué cayó Alfonso XIII, 154-56.

29. Es de notar cómo para Cambó, político regionalista, defensor de los intereses de Cataluña, con Prat de la Riba al frente de la famosa "Liga Catalana". Maura representaba la verdad y la virtud de un movimiento de oposición: su gobierno de 1907 a 1909 fue "el intento más serio, más vigoroso y más honrado — palabras textuales de Cambó- de una renovación de la vida pública. (J. PABON, Cambó, 356-57, 417).
} 
ción antes y después del desastre colonial. Acerca de la tan decantada y no menos discutida (reforma municipal", en el Archivo de Agustinos-Filipinos de Valladolid se conserva una "Circular reservada), dirigida por el Arzobispo de Manila al provincial de los Agustinos, del tenor siguiente: "Con fecha I4 del actual (octubre de I893) hemos dirigido a los RR. PP. Vicarios Foráneos de este Arzobispado, con el carácter de Reservada, la siguiente circular:

"En vista de que se cita ya en vías de plantear la nueva ley de reforma municipal, creemos llegado el caso de comunicar a V. R. las impresiones propias que nos sugiere el estudio de esa ley, y como consecuencia de ellas señalar algunas reglas generales, a las que creemos debe ajustarse la conducta de los Párrocos y Vicarios en orden a su planteamiento y sucesivo desarrollo... =

$=$ Empezaremos por decir que la ley en su conjunto nos ha parecido justísima por dos razones : la primera, porque su objetivo es dar vida económica a los pueblos, que al presente no tienen; y la segunda, porque el conjunto de sus disposiciones demuestra el loable propósito que guía al Legislador de deshacer la máquina de sistemáticos abusos con que se venía vejando y desmoralizando a los pueblos. $=$ Claro es que no podemos formarnos la ilusión de que con la nueva ley, se van a cerrar todas las puertas de los abusos; pero siempre es loable el intentarlo y no debe escatimarse apoyar a la autoridad que a tan noble fin aspira. Aunque no sea dable en este orden humano llegar a la perfección, debe evitarse el caer en el pesimismo de suponer incorregible todo abuso establecido. Por nuestra parte abrigamos la esperanza de que cooperando eficazmente los Párrocos, se ha de lograr con el planteamiento de la nueva ley, por lo menos atenuar los desarreglos de más bulto, que se han introducido en la administración municipal de los pueblos. = Además de las ventajas materiales que la nueva ley lleva a los pueblos, lo que de por sí es ya bastante para hacerla simpática al Clero; en otro orden, que es el de la moralidad pública, y por cuanto que en este orden deshacer un SISTEMA de abusos, que comprometían grandemente las conciencias y por ello dificultaban no poco el gobierno espiritual de las almas, se hace más digna de nuestro aprecio y merece que por nuestra parte no escatimemos el apoyo y cooperación que sean dables para que se plantee y rija con la posible perfección. Los prácticos en la cura de almas saben bien que se puede luchar contra abusos individuales, pero que es infructuosa la lucha 
cuando el abuso viene impuesto y es como resultado forzoso de un SISTEMA, que es lo que por punto general sucedía. No necesitamos insistir sobre este particular en que tanto V.R. como los Párrocos to. dos conocen por dolorosa experiencia mucho más de lo que pudiéramos decir. = Pero sea cual fuere el valor real y práctico que a la Refor. ma se conceda y las diferentes apreciaciones que sobre ella puedan formarse, una cosa es cierta y se impone como regla general de conducta para los Párrocos, y es la necesidad de evitar con suma prudencia cualquier pretesto o motivo que pudiera invocarse mañana por virtud del cual se pueda atribuir al desvío u oposición de los Párrocos la imposibilidad o dificultades para el planteamiento de la Reforma. El exceso de prudencia en esta parte es tanto más necesario, cuanto que a las dificultades naturales con que ha de tropezar toda reforma, se han de añadir las que provoquen INTERESES lastimados, siquiera no sean legítimas, los cuales con sagacidad mundana han de buscar apoyo para sostenerse, y sin duda sería muy especioso el que pudiesen encontrar en los Párrocos. Esto no sería óbice para que mañana los representantes de esos intereses se exhibiesen ante el público escandalizados de la oposición sistemática que a toda mejora opone el Párroco regular, echando sobre él la odiosidad del fracaso si tal aconteciese. A todo trance hay que evitar ese lazo que, según podemos observar, se va tendiendo en algunas partes. Por eso no debe creerse fácilmente en la sinceridad de los que se presentan criticando la nueva ley, y sobre todo, si eligen como punto de crítica el papel desairado que representarán los Párrocos en los tribunales, el depresivo de los Vicarios, en las Juntas Provinciales, etc., etc. No es juicio temerario el creer que el fin de tales insinuaciones, lejos de ser celo por el prestigio del Párroco, sólo es deseo vehemente de que el Párroco se aísle del Tribunal, con lo cual, dicho se está, que la reforma sería un desastre y pronto vendría sustituída por otra. La regla del CUI PRODEST...... será aquí norma segura para determinar quién es el interesado en que la reforma no prospere y dará a su vez la pauta al Párroco acerca de la conducta que sobre el particular debe adoptar. = El caso no sea excusado el que por parte de V.R. se acentúe ante los Párrocos de su distrito la fuerza que detrás de sí tienen para sostenerlo en las luchas legítimas que hubieren de afrontar, primero en la Junta Provincial y después en cl Consejo de Administración. Que tengan la seguridad de que en estos Centros por donde han de tramitarse los incidentes municipales, en- 
contrarán apoyo sus reclamaciones que, como es de suponer, serán siempre legítimas. Y cuando los pueblos vean que no luchan aislados, con el crecimiento de su prestigio, irán decreciendo las dificultades. Nuestro criterio en este asunto de la ley municipal respecto a la conducta que deben seguir los Párrocos los resumimos en la siguientes reglas: $=\mathrm{I}^{\mathrm{a}}{ }^{\mathrm{a}}$ No deben los Párrocos mostrarse indiferentes respecto al planteamiento de la reforma; antes bien, conviene que por su parte allanen todas las dificultades. $=2{ }^{\mathrm{a}}$ Cuando éstas se discutieren ante Gobernadores y otras personas respetables, el criterio del Párroco debe ser siempre favorable a la nueva Ley defendiendo su viabilidad y que con buena voluntad por parte de todos no sólo pueda plantearse, sino que será beneficiosa a todos. $=3 .{ }^{a}$ Por tropiezos que se presenten a los Párrocos, sean por elementos hostiles que existan en algunos pueblos, sean por los de fuera, no deben retirarse y renunciar a la no intervención legítima que les corresponde en los nuevos municipios. Muchas de las dificultades serán del momento y hay que esperar a que se corten desde arriba. $=44^{\circ}$ Sería triste y de muy mal efecto que los Párrocos aparecieran divididos y no siguieran conducta uniforme en lo referente a la ley municipal. Los PP. Vicarios harán una obra buena promoviendo esa uniformidad y llamando la atención de los que en esta parte desentonaron. $=5 .^{\circ}$ En las Juntas Provinciales los PP. Vicarios no deben arredrarse, así se queden solos, cuando se trate de defender derechos legítimos o corregir abusos de cuantía. El voto particular que en estos casos procede les da medios de buscar apoyo en espera superior. $=6 .^{*}$ La última regla las comprende todas y es que sea tal la conducta del Párroco en todos los particulares de la Ley, que en lo posible evite todo pretexto de censura a fin de que mañana si la Ley fracasare no pueda echarse sobre la clase el cargo de haber contribuído directamente ni indirectamente a su fracaso. Las indicaciones que a V.R. hacemos en esta circular RESERVADA le darán ocasión para tratar con todos los Párrocos de su distrito sobre la necesidad de que todos adopten conducta uniforme y prudente en el particular de la Reforma)" ${ }^{30}$.

La reforma de Maura apareció en la "Gaceta de Madrid» el 22 de mayo de 1893 . Por real decreto se modificaba la estructura del Consejo de Administración y la Administración de Justicia ; y establecía un

30. ARCHIVO AGUSTINOS de Valladolid. n.o 3800 . 
nuevo régimen municipal para los pueblos de las principales provincias del archipiélago, como Luzón y Visayas; además fijaban los gastos e ingresos del Estado en la totalidad de las Islas durante el ejercicio económico de 1893 a 1894; reorganizaban los gobiernos civiles y político-militares y declaraban libre la venta de billetes ${ }^{31}$.

Pues bien, tan pronto se conocieron por su lectura en el Parlamento y por su divulgación en la prensa las reformas de Maura, fueron muy discutidas en las islas afectadas por el proyecto, desde luego; pero también en Madrid y en los círculos políticos del país todo; unas veces - muy pocas - con atención, objetividad y competencia, a tono con la importancia del empeño acometido por Maura; y en otros casos, con mezquina intención política, ya que proporcionaba nuevas armas a los enemigos del Gobierno ${ }^{32}$.

Maura conservó su serenidad y en el Congreso hizo una defensa muy meditada de sus reformas, que, de haberse llevado a cabo, como dijeron en su día algunos cabecillas de insurrección, le hubiera evitado la guerra y no hubiera sido posible la revolución.

La politica de atracción, usada en Filipinas por el general Blanco, el cual se había inspirado en la política de Maura, fue interpretada de formas muy diversas. No pocos la calificaron de absurda y ridícula. "No entendemos - escribía un contemporáneo, lo que significa la política de atracción, a no ser que se defina juiciosamene como la ce. sión de todos nuestros derechos políticos en favor de los indígenas, para asimilarlos a nuestra condición y raza y para no violentar sus rebeldías, dispuestos en toda ocasión a cometerlas) ${ }^{33}$.

Para juzgar objetivamente de este asunto, tenemos que colocar. nos en 1890 , cuando se pensaba y se hablaba todavía de colonialismo. Hoy la conducta de Maura y del general Blanco saldrían mucho más favorecidas de los teóricos y teorizantes que en aquel momento en que se consideraba a Filipinas, por una parte, como la última y más rica colonia de cuanto fue imperio Español, y por otra, con un pueblo insuficientemente preparado para darle la independencia y la emancipación de España, de la metrópoli, a pesar de que cuenta con inte.

\footnotetext{
31. M. Fernandez almagro, Ha. Politica de la España Contemporánea, Madrid 1959, 191.

32. Ib. 195 .

33. J. M. CASTILLO, EI Katipunan, 64.
} 
lectuales del tipo de Rizal y con soldados como el que luego fue general Aguinaldo.

Los testigos de excepción son, en este punto, muy expeditivos. Veamos lo que dicen:

Los jefes de las provincias que, con honrosas excepciones, des. empeñan su cargo contando las horas y los minutos que les restan de estancia en el país, y contando y recontando el producto de unos sueldos que apenas ganaron, y los resultados, tal vez, de alguna dulce granjería, no se han ocupado de estas cuestiones que surgían a diario; no han tomado nota de las evoluciones que venía haciendo la serpiente de la revolución. No se han cuidado de contener el desarollo de la soberanía indígena alentada por la atracción maldita, sino que, por el contrario, se entretenían en mantener una lucha pública y desprestigiosa para sus personas con el párroco, con el administrador de $\mathrm{Ha}$ cienda, con el interventor, con todos los elementos oficiales; y éstos. siguiendo el propio ejemplo, mantienen entre sí y con aquél igual lucha; y en estas danzas poco edificantes quedaban por el suelo no sólo la dignidad nacional, sino también el prestigio y el buen nombre de las autoridades.

Con todo esto, los naturales se aprovechaban de la ocasión, arrimándose a aquellas personas de las que más ventajas podían sacar, sacrificando un puñado de chapecas de plata, alguna pareja de caballos o cosa por el estilo.

De todos era notoria - y los religiosos lo denunciaban constantemente - que la administración pública estaba llena de inmoralida. des ${ }^{34}$. Eran una administración que dependía de los vaivenes políticos y de la fuerza mayor o menor de los partidos. Una administración sin estabilidad, sin garantías, sin condiciones de ningún género, te. nía que abocar al desastre y con el resultado final que todos conocemos.

Esta era la triste realidad en Filipinas. Lo que pasaba era que solía, como siempre, ocultarse, y emprenderla contra los inocentes. Pero, de vez en cuando, surgía una pluma ágil y vigorosa y lo con-

\footnotetext{
34. Es significativo y hasta elocuente lo que se dice sobre este particular: Cargos tan de. licados como son los que se refieren al mando y administración de las colonias se dedican a remediar desgracias de la fortuna, a socorrer miserias atraidas por el despilfarro y el vicio, y no se confían a parte curtida en la administración, de honradez acrisolada, de condiciones propias y ostensibles, y de esta suerte las colonias se atrofian y el mal cunde, mientras la yernocracia prospera y se engrandece" (J. M. CASTILLO, EI Katipunan, 66).
} 
taba a secas, con llaneza, como debe decirlo un hombre honrado que no tiene aspiraciones políticas ni le envanece la esperanza de alcanzar un puesto importante en la Administración del Estado.

Y si había que culpar a alguno del desastre, siempre quedaban "los frailes", a los que se les hizo una guerra sin cuartel y sin nombre; guerra a la cual todos apostaban su tizona: los indios llevados por el odio de raza, los mestizos por el ansia de independencia y de libertad, y los españoles, bien porque no gustaban de sus advertencias y (sermones), bien haciéndoles el vacío o mostrándose indiferentes con ellos.

Cuando la voz de la pasión se extinga y se calme el hervor de la lucha, la razón serena e imparcial se encargará de pedir a los hombres sus alientos y energías para condenar, cual se merecen, a los caudillos que labraron nuestra ruina.

Esto se escribía en el año 1900 , apenas consumada la tragedia nacional. Y lo escribía uno de los testigos de mayor excepción, el P. Joaquín D. Durán, el cual nos dejará un opúsculo duro, realista y tremendo, en el que nos relatará los episodios de la revolución filipina.

Ahora que ha pasado más de medio siglo, y cuando, efectivamente, se ha extinguido la voz de la pasión, de la que no estaba ajeno al propio agustino autor de los (episodios), podemos decir con serenidad objetiva que, admitido ese algo providencial y ese momento histórico que tenía que llegar para Filipinas, como había llegado bastantes años antes para América, la culpa del desastre nacional habría que echársela en una gran parte a los ineficaces y acomodaticios gobernantes españoles. Cuando estudiemos, más adelante, las causas de la insurrección, allá lo veremos más de cerca.

En cuanto a otros hombres de Estado y autoridades civiles que, de un modo o de otro, intervinieron en los asuntos de las colonias, debemos citar aquí a D. Francisco de Silvela, jefe del partido conservador a la muerte de Cánovas, el cual, en plena crisis puso de manifiesto un patriotismo íntegro, intentando un gobierno solícito y señalando el grave problema español. Silvela publicó entonces en «El tiempo" su famoso artículo titulado (Sin pulso», que fue como la iniciación de la literatura (del desastre». En este artículo señalaba el sin- 
gular estado de España; pues (cdonde quiera que se ponga el tacto -dice- no se encuentra el pulso) ${ }^{35}$.

Silvela, después de la derrota, caería en un pesimismo tal, que en I903, como ya queda insinuado al tiempo de enjuiciar la política de Cánovas, no parecía el mismo. Silvela se retirará del gobierno y dejará hacer. Está decepcionado; y tiene pocas esperanzas de recuperación.

El caso Moret ya es distinto. Moret era un hombre guapo y elegante; de cultura brillante, si no profunda y sobremanera elocuente. Era, a la vez, de voluntad flaquísima, nula a veces. Realidad ésta que registran sus biógrafos y que parecía sentirse en el contacto de su. mano, "un poco fofa, blanda, senil»" ${ }^{36}$.

Con los años, se ennobleció su figura, tornóse su ideário anacrónico y desorientado, y disminuyó su voluntad, siempre flaca. Quedó en una fachada excelente, tras de la que pudieron ocultarse y actuar voluntades malas y ajenas. Dióse en él, por modo muy claro, la paradoja de la figura y la contrafigura del político. Moret era la corrección misma : en el atavío, en los modales, en las palabras. Y manejado por unos y por otros, su conducta fue una serie de escandalosas insurecciones, de irritantes inconsecuencias, de faltas gravísimas contra todas las normas del buen sentido y del buen gusto. Pequeñas perfidias, como la de (el papelito», con que derribó por la espalda a López Domínguez, grandes prefidias, como la maniobra de 1909, contra Maura, nos ofrecen puntos de serias reflexiones sobre este personaje y la política equivocada de aquellos días.

Moret se sorprendió siempre del resultado, adverso al cabo para él, pues obraba empujado por otros $y$, generalmente, sin plena conciencia del daño que producía. ${ }^{37}$.

Esto nos explica que, al tiempo de juzgar al ministro de la oposición, tanto eclesiásticos como civiles, carguen sobre él muchas de las culpas de aquella equivocada política, hasta que fuera sustituido por Canalejas, en quien los liberales parece encontraron un verdadero jefe de partido.

\footnotetext{
35. F. SILVELA, Artículos, Discursos, Conferencias y Cortes, (Madrid 1923), II, 493.

36. A. del OLMET y GARCIA CARRAFA, Moret, (Madrid 1913), 13.

37. J. PABON, Cambó, 264-65.
} 


\section{b. Las Autoridades Militares}

Como ya hicimos notar en el capítulo anterior, nos interesa destacar en éste, no tanto la obra de gobierno, o el mando militar en 'a colonia durante la última etapa del dominio español, cuanto las vicisitudes por que pasaron las Autoridades Militares, sus actos inmediatos, sus decisiones y, esto sobre todo, la opinión de las mismas ante el problema capital de Filipinas y los acontecimientos revolucionarios que se iban sucediendo y como atropellándose hasta desembocar en la gran revolución de 1896 y definitivo desastre de 1898 .

Para ello, creemos conveniente que antes de tratar de los últimos "Gobernadores Militares» que hubo en Filipinas, recordemos algunos nombres beneméritos que les precedieron en el mismo cargo, y que trataron de encauzar las cosas del mejor modo posible, aunque muchas veces se quedara todo en buenos propósitos y mejores deseos.

Ya por el año I 860 nos encontramos con un gobernador general, José Lemery, que se dedicó con gran esfuerzo a extirpar vicios y abusos, introduciendo mejoras y contribuyendo a que dejara de ser proyecto el código de procedimiento penal, formado por el oidor Aguirre Miramón.

Lemery consiguió que los productos de aquellas islas figurasen ya en las exposiciones; ordenó que el dinero que se gastaba en fiestas para recibir a los Capitanes generales se aplicase a obras de utilidad pública, tan escasas en la ciudad de Manila; creó el gobierno Político-Militar en las islas Visayas, haciendo otro tanto en la de Mindanao ${ }^{1}$.

Es en este momento cuando, aparte de la ocupación de Formosa ${ }^{2}$. se consiguen señalados triunfos ante los piratas musulmanes que amenazaban la costa; se efectúan algunas operaciones militares en la rica vega de Mindanao contra los moros, siendo entonces tan excelen-

\footnotetext{
1. M. LAfUente - J. VALERA, Historia General de España, (Barcelona 1890), XXIII, 8, 370.

2. En este mismo gobierno de Lemery tuvo lugar la ocupación de la isla de Formosa por las tropas españolas, conquista que a juicio del historiador, "era un absurdo", pues sobre ser discutible la utilidad que de tal empresa sacábamos, suscitó incidentes y complicaciones con Francia e Inglaterra que tenían sus grandes intereses políticos y mercantiles en aquellos mares y latitudes.
} 
te el comportamiento de las tropas y de tal manera ayudaron en la empresa los misioneros de la isla, que, además de obtener sumisiones de valor, consiguieron que los llamados (manobos», vejados y perseguidos por los moros, pudiesen abandonar al fin sus guaridas y se acogiesen al favor de los españoles.

En 1862 está de gobernador general Rafael Echagüe, un hombre pleno de aciertos y fiel secundador de las tareas de su antecesor. Efecto de la confianza que los españoles inspiraban -escribe el historiador Lafuente-, se presentaron en Ilocos, procedentes de varias rancherías, considerable número de tinguianes infieles, deseando abrazar nuestra religión y formar pueblos; se convino con ellos cederles terrenos para el cultivo del tabaco y arroz, dándoles los útiles de labranza y eximiéndoles por cierto número de años de toda contribución; se redujo a muchos infieles de Camarines; en las provincias al norte de Luzón efectuaron nuestras tropas expediciones contra los igorrotes, y en el distrito de Bentoc se ejecutó una en mayo de 1863 y otra en 1864 , sufriendo los igorrotes un justo y ejemplar castigo por las tropelías que habían cometido, experimentando también el debido escarmiento varios malhechores que se levantaron en la isla de Negros, no escaseando tampoco en las inmediaciones de Manila ${ }^{3}$.

El gobierno de Madrid - gobierno de O'Donnel- presta esmerada atención a las islas y desea satisfacer las necesidades de sus habitantes. Al efecto le dan a Echagüe instrucciones reservadas para que procurase demostrar que en aquellas provincias estaba garantizado el ejercicio de una prudente y útil libertad; que se administra$\mathrm{ra}$, se respetara la seguridad de las personas y de las propiedades, y se fomentara la riqueza pública; que se extirpara la administración de pandilla que habían establecido algunos empleados; que desterrara fórmulas introducidas por algunos de sus antecesores, propias solamente del poder real; que bajo ningún concepto se mezclara la acción de la autoridad superior en nada que se refiriese a la adminis. tración de justicia; que armonizara con los institutos religiosos que estaban prestando eminentes servicios y prodigando su vida por la re. ligión y la patria; que, si naciones extranjeras solicitaran auxilios, con- 
cediera los que no pudieran comprometer al gobierno en su política y comercio internacional; que, llamando la atención el número considerable de razas que existía sin reducir al cabo de tres siglos, aun cuando hubiera dificultades, se carecía de un sistema constante de ocupación del territorio poblado por los infieles, siendo indispensable que la dominación española llegase a ser una verdad, lo que podría conseguirse efectuándose periódicamente expediciones por los jefes de las provincias, y se combinase por ellos en sus relaciones con las tribus salvajes la energía en los casos en que fuese necesaria, con la prudencia y aun con la dulzura en otras ocasiones, dándose en esta civilizadora empresa a las misiones religiosas la parte que en derecho les correspondía; y se hacían convenientes observaciones sobre todos los ramos de la administración pública ${ }^{4}$.

Era evidente que había muchas cosas que reformar en Filipinas; pero tenían que ser bien estudiadas y nunca pensaran que fuesen iguales a las que se podían implantar en la Península, y menos que, al tiempo de efectuarlas, se olvidasen del modo de ser, carácter y costumbres de sus habitantes. De tal manera, que ya se preveía y aconsejaba que, más que a ciertas reformas, había que atender a las personas que allí se enviasen. "Vayan ilustradas autoridades y hombres y competentes empleados y serán grandes los progresos que se hagan en la obra de la sumisión que debe ser constante y en la de la perfecta civilización de aquellas islas) ${ }^{5}$

Como es de suponer, hubo opiniones para todos los gustos. Algunos fueron de parecer que el mando de las islas debía recaer única y exclusivamente sobre una persona. Pero otros, como Escosura, comisionado de exprofeso para estudiar las necesidades más urgentes de la colonia, abogaron por repartir el gobierno entre varios que ostentarían distintos cargos estatales: militar, político y económico.

Miramón dejará escrito, sobre el particular, una interesante "Memoria), reservada e inédita, en la que dirá, entre otras cosas, lo que sigue: (nada de expediciones militares, si no es para causas explicables. No necesitamos conquistar territorio, sino conquistar habitantes: las armas los ahuyentan, como ha demostrado la experiencia, y

4. M. LAFUENTE, o.c. 373.

5. Ib. 374 . 
territorios sin habitantes no nos servirían sino para muchos gastos y muchos malos ratos. Hartas provincias tenemos incultas en Filipinas por falta de brazos. La historia y los resultados han juzgado las expediciones llevadas a cabo en años anteriores: pregúntese la que fue la última de Balabac. La fuerza y riqueza de un país no consiste en su extensión, sino en el número de sus habitantes. Casi todas las re. formas se han hecho sin el debido conocimiento del país y principiando por el envío de empleados, antes de organizar los empleos mismos, o sea, los servicios a que habían de dedicarse. ¡Cuántos hechos de esta naturaleza podríamos presentar, que no sólo ruborizarían, sino que indignarian a toda conciencia honrada! ${ }^{6}$.

La misión de Escosura fue excelente; y excelente también la "Memoria» que dejó escrita dando cuenta de la misma. Pero, como en tantos casos y ocasiones, el gobierno de Madrid no la supo aprovechar. No hubo visión política ni administrativa en la Metrópoli. Filipinas, por fuerza, debía quedar muy lejos de la capital de España.

Porque entonces debió aplicarse más la atención al mar de Mindanao, considerado como el (Mediterráneo») de aquel vasto archipiélago, vehículo de comunicaciones y del mismo comercio interior. Escosura estudiaba y comparaba nuestros sistemas coloniales con los de Holanda y Gran Bretaña; y sacaba la conclusión, no sólo de que no había paridad entre ellos, sino que ni siquiera nos deteníamos a copiar de ellos - inunca a explotarlo como ellos! - aquel comercio y aquel provecho que sacaban de sus colonias. Desgraciadamente, para España - concluye Escosura - tanto los gobiernos como las autoridades, casi todos y todas, no sólo han sido rémora para el necesario progreso de nuestras posesiones de Ultramar, sino un perjuicio; y si éste no le causaron por malicia, lo hicieron por ignorancia. Sólo desconociendo completamente la historia de Joló, no tomándose la molestia de pedir antecedentes a nuestros archivos, se podía conceder pensión a los que habían sido tributarios de España; pero aún se ha hecho más: aún, con temeraria imprevisión, se ha dado motivo a que se desconozca nuestro perfecto derecho al dominio completo de aquellos territorios. De esto, que entraña mucha gravedad, nos ocuparemos a su tiempo.

6. b. 374 
Si se tratara de una isla insignificante, podría disculparse la inercia, el abandono, la ignorancia y la gran culpabilidad de algunos de nuestros gobernantes; pero prescindiendo de su grande extensión, se trata de una población de 57 islas, que son las que forman el grupo de Joló, siendo las principales Joló, Tonquil, Bealún, Bocatuán, Balanguingui, Pangutarán y Pandacán, midiendo la de Joló, que es la mayor, sobre treinta leguas de circunferencia, contando 44 pueblos?.

Al general Echagüe sucede en el mando don Juan de Lara e Irigoyen, un hombre de pésimo recuerdo en Filipinas, que se dedicó a dar ostentosas fiestas, mientras el pueblo sufría las más extremas necesidades.

En seguida será sustituido por el general José Laureano Sanz, el cual trató de poner remedio a la inmoralidad administrativa reinante, obrando quizá con demasiada precipitación y dureza antes de conocer el personal con que contaba para su delicada cuanto espinosa tarea.

El año I867 Filipinas va a contar, por fin, con un excelente gobernador en la persona del general José de la Gándara, auxiliado eficazmente por Tomás Rodríguez Rubí, como intendente de Hacienda y por los corregidores Oraá y Azcárraga, más el regidor conde de Avilés, sin olvidar a la Guardia Civil que venía a sustituir en el Archipiélago al viejo y gastado cuerpo de cuadrilleros, el cual, lejos de ser una garantía del orden, llegó en ocasiones a considerársele como un peligro por su relajamiento y servir de instrumento de ambiciosas autoridades locales.

Para proteger el comercio, se abolieron los derechos de exportación; y para fomentar las obras públicas, se eximió de todo pago los materiales extranjeros; se derogó la prohibición de prestar a los indígenas más de cinco pesos; se proyectó garantizar y regular la propiedad rural de las islas, colonizar a Mindanao, reducir a Joló, crear gobiernos civiles en las provincias del Archipiélago, hacer de regadío la mayor parte posible de los terrenos de las islas, establecer una línea de vapores correos a Singapore, que funcionó años después; autorizóse a unos particulares a fundar una escuela de artes y oficios, su-

7. Ib. 378 . 
primida por el general Izquierdo antes de abrirse; se dio algún impulso a la instrucción primaria; suprimióse la jurisdicción de Hacienda y la contencioso-administrativa, hoy restablecida; se unificaron los fueros, excepto en lo referente a los eclesiásticos, que continúa sin alteración; prohibióse a los empleados públicos comerciar, tener cargos de corporaciones, ni ejercer apoderamientos; se suspendieron las remesas de tabaco por administración de Australia y se procuró atender a este importante ramo ${ }^{8}$.

En 1869 tomaría el mando de Filipinas el general Carlos María de la Torre, produciéndose ya entonces un chispazo de manifestación política alarmante en Manila, y que serviría de precedente lamentable para sucesos ulteriores.

Durante el gobierno del general Izquierdo - $187 \mathrm{I}$ - fue debidamente atendida la instrucción primaria y recibió un gran impulso la colonización de la isla de Mindanao donde dejó gratos recuerdos el brigadier Golfín; creáronse colonias penitenciarias; adquirió gran importancia la naciente población de Puerto Princesa de la extensa isla de la Paragua, y se crearon relaciones comerciales que fomentaron la civilización de los pueblos ${ }^{9}$.

Son estos los días de la insurrección de Cavite, precedida de revueltas y sublevaciones parciales de cabecillas, como el famoso Soro, el cual sostuvo una heroica resistencia con la Guardia Civil de Imus antes de ser hecho prisionero.

La insurrección militar de Cavite ocurrió el 20 de enero de 1872 , comenzando por el destacamento de Artillería de la ciudad "Fuerza de San Felipen, y siguiendo por las tropas del cuartel que se adiestraban para la defensa del arsenal.

Las fuerzas españolas leales a Madrid sofocaron la insurrección tomando al asalto la fortaleza y pasando a cuchillo a los insurrectos. Observemos de pasada cómo los principales cabecillas de aquella fracasada insurrección fueron dos cabos de infantería de marina, acusados anteriormente de traición a la patria; pero fue inspirada y alentada por un grupo de sacerdotes del clero secular, indígenas todos ellos, a los que hubo de dirigirse severamente el Arzobispo 
de Manila prohibiéndoles leer periódicos democráticos venidos de España ${ }^{10}$.

En enero de 1873 , el general Izquierdo es reemplazado por Juan de Alaminos. Apenas posesionado de su cargo, se encontró con la grave cuestión del nombramiento de Alcalá Zamora para obispo de Cebú, nombramiento que fue rechazado por la Santa Sede. Un espinoso y delicado asunto que sólo se resolvería por la inesperada muerte del prelado antes de que llegara a tomar posesión de su silla episcopal.

Don José Malcampo llega en junio de 1874 . Su principal tarea estuvo en sanear el caos burocrático que existía en las islas, para lo cual pidió y se le concedieron amplias facultades para hacer y deshacer en el nombramiento de cargos administrativos, cortando de este modo muchos abusos. Malcampo organizó también una poderosa expedición a la isla de Joló, embarcándose él mismo en la fragata "Carmen» y en compañía del contraalmirante Manuel de la Pezuela, segundo jefe de la misma. La isla fue conquistada y ocupada, construyéndose el fuerte llamado "Alfonso XII» y el campamento "Nuestra Señora de las Victorias). Malcampo consiguió con esta hazaña los títulos honoríficos de conde de Joló y vizconde de Mindanao, para sí y sus legítimos sucesores.

Pero las cosas no rodaban bien para los españoles en Filipinas, como no rodaban bien en las posiciones del Mar de las Antillas. América era ya casi toda independiente; y Cuba, la última colonia española del Nuevo Mundo, daba muestras no sólo de insurrección, sino también de abierta guerra contra sus dominadores.

Al tomar el mando de las Islas Filipinas el general Domingo Moriones, sucesor de Malcampo, hubo de entregarse a restablecer la disciplina un tanto relajada entre los soldados, los cuales llegaron incluso a sublevarse en cierta ocasión contra el glorioso apaciguador de Joló.

\footnotetext{
10. "Levantemos, pues, la voz -decia el Sr. Arzobispo de Manila-, inspirados también por el deber de nuestro cargo pastoral, para anatematizar con toda la indignación que se merece la insurrección provocada entre las sombras por deslealtad de algunos sacerdotes del país que, para escándalo de la religión de la Iglesia, han tomado por desgracia una participación desatentada en tan punible pensamiento, uniéndose en vil consorcio con otros hijos del país tan descarriados como ellos".
} 
La Hacienda pública estaba, asimismo, descuidada y se debían grandes cantidades por cosechas atrasadas a los productores de tabacos de Cagayán e Isabel. La crisis monetaria, ocasionada por la entrada de moneda extranjera, se pudo contener gracias a algunas reformas económicas que no dejaron de ser parciales y de circunstancias. También se realizaron mejoras en el fuerte y campamento de Joló.

Por todo ello, los historiadores elogian el gobierno de Moriones calificándole de fructífero y provechoso para el Archipiélago y la península ${ }^{11}$.

Pero tenemos que llegar ahora a los años más cruciales de la historia del viejo Archipiélago magallánico y a enjuiciar a los hombres que tuvieron que llevar las riendas de su gobierno.

Uno de los hombres que más se destacaron en estos últimos años del siglo XIX fue Don Fernando Primo de Rivera, abuelo del fundador de la Falange, José Antonio, y padre del famoso dictador Don Miguel Primo de Rivera. Sobre este hombre se formularon en su día juicios encontrados.

He aquí lo que escribe un autor que lo conoció y trató en Filipinas durante los aciagos días de su gobierno. A raíz de la paz de Zanjón entre insurrectos y españoles, "los filipinos, que en las anteriores algaradas habían permanecido fieles al lado de la legalidad, estaban ahora como estupefactos de las caricias que la madre España hacía a sus díscolos hijos y el parangón entre leales y desafectos hería la vista con colores mortificantes para los primeros. Porque hay que confesar que los adictos a la causa nacional no recibieron más premio a su lealtad que la pérdida de sus animales de trabajo, mal custodiados por la tropa española, juntamente con el menoscabo de sus intereses nunca bien garantizados por el gobierno, mientras que aquellos ingratos, tan injustamente levantados contra España, que derramaron con criminal osadía la sangre de mil inocentes víctimas, eran precisamente los agasajados por la patria, no solamente con amplísimo indulto, sino pagándoles con generosidad digna de mejor aplicación, los pocos fusiles que entregaban.

Los díscolos hijos eran tan queridos del Sr. Primo de Rivera,

11. LAFUENTE; "Ha. General de España" tomo 24, pág. 408. 
que tenía dadas órdenes rigurosas contra todos aquellos que los molestaran en lo más mínimo, amordazando de esta manera a todos los sensatos españoles que, en sus plausibles deseos de ver siempre muy alta la honra de su querida bandera, se condolían amargamente viéndola mancillada y escarnecida por concesiones irritantes y debilidades perniciosas) ${ }^{12}$.

El testimonio del Sr. Pellicena es totalmente condenatorio y sus frases contra el marqués de Estella son realmente terribles. No vamos a escribir todo cuanto escribió contra el gobernador general de Filipinas; pero sí algunos juicios. "Al marqués de Estella -escribele constaba de una manera indubitable, en el mes de marzo de I898, que los elementos revolucionarios acogidos al convenio de Biac-na-bató se reunían y se agitaban, esperando sólo que fueran repatriadas las tropas expedicionarias para volver a levantar sus secuaces en los mismos puntos que lo habían efectuado anteriormente...

Siendo evidente a todas luces - prosigue Pellicena- que al marqués de Estella abrigaba perfecto conocimiento del estado del país y de los planes de los revolucionarios, se preguntará: ¿ por qué no era franco con el gobierno exponiéndole el verdadero cariz de la situación?

«El general Primo de Rivera, que no tiene un pelo de tonto - añade Pellicena - veía echarse encima la guerra con los Estados Unidos; sabía de la existencia de la escuadra de Dewey en Hong. Kong; no ignoraba todos los manejos de los revolucionarios; conocía mejor que nadie las complicaciones que aquí iban a sobrevenir; y cómo había engañado al gobierno sobre la verdadera situación de Filipinas, no encontraba otro medio mejor de salir del compromiso que abandonar, cuanto antes, estos territorios»" ${ }^{13}$.

Otro escritor, más importante, más ecuánime y objetivo, el cítado Manuel Sastrón, nos enjuicia también en su libro "La insurrección de Filipinas" la conducta del marqués de Estella». Un Real Decreto de fecha 24 de marzo ( 1897 ) - escribe- había nombrado

12. J. D. DURAN, Episodios de la revolución fllipina, 18 .

13. J. PELLICENA, La verdad sobre Filipinas, (Manila 1900), 29. 
para suceder al Sr. Marqués de Polavieja en el mando superior de estas Islas al Exmo. Sr. D. Fernando Primo de Rivera; mas habiendo de regresar a la Península el primero de dichos generales con la urgencia que exigía su quebrantado estado de salud, el gobierno de S.M. encargó el mando superior del Archipiélago al general Lachambre el cual lo ejerció desde el 15 de abril hasta la llegada del Sr. Marqués de Estella, que tuvo lugar el 25 del mismo mes) ${ }^{14}$.

El 25 de abril de 1897 fondeaba en la bahía de Manila el vapor correo transatlántico "Montevideo» trayendo a su bordo al nuevo Gobernador General, uno de nuestros príncipes de la milicia, el cual en su honrosa hoja de servicios ya consignaba más de tres años de mando superior en estas islas.

Si entoces el marqués de Estella supo ganarse la simpatía de todos, en esta situación no iba a estar a la altura requerida. Es verdad que como militar tuvo sus aciertos; pero desde el punto de vista político, fracasó rotundamente. El prestigioso general se engañaba pensando que aquellos eran días de paz y de buen entendimiento con los naturales. Se había operado un cambio durante su ausencia y el ilustre soldado no acertaba a verlo. Al final, Primo de Rivera se vio plenamente defraudado en sus optimistas previsiones.

Que el gobernador de Filipinas se engañaba con las intenciones de los tagalos, no hay duda; pero que procedió siempre con rectitud de intención y con los deseos de salvar lo que consideraba en peligro, tampoco puede negarse. Testimonio elocuente son sus instrucciones de 18 de junio de 1897 dirigidas a los gobernadores militares, comandantes de plaza y jefes de destacamentos.

Resumiendo el largo texto de las mismas, vienen a decir lo siguiente: En todas las releliones reprimidas por la fuerza, vienen a quedar unas partidas de hombres doloridos y resquemados que seguirán inquietando a la autoridad, y sembrando la desconfianza y alarma en los espíritus poco reflexivos.

Estos males alcanzan su mayor desarrollo cuando las autorida-

\footnotetext{
14. E! historiador elogia la prudencia, la bravura y la conducta del general Lachambre hasta llegar a decir que "hubiese durado muchos más días en el mando, si las palpitaciones de la opinión pública se ponderasen con más frecuencia $v$ a ellas se atendiese desde las esferas de la gobernación del Estado". (MANUEL SASTRON; La insurrección de Fillpinas, il, $1,257$.
} 
des civiles se contentan solamente con el deber de vigilancia; pero si interpretan en su verdadero sentido el espíritu de nuestras sabias ordenanzas, puede que se remedie algo la situación.

El capitán general está dispuesto a conseguir el orden poniendo para ello "los medios más enérgicos y exigiendo responsabilidades a todos los jefes de capital, cabecera o pueblo donde haya guarnición).

Y a continuación da normas concretas de cómo debe llevarse la vigilancia y la disciplina ${ }^{15}$.

Por lo que se refiere a la conducta que siguieron los religiosos con la primera autoridad del Archipiélago, aunque no estuvieran muchas veces de acuerdo con sus decisiones, nos proporciona pistas importantes una circular del Superior Provincial de los Agustinos fechada el 1 de febrero de 1898 . El P. Manuel Gutiérrez comunica a sus religiosos la decisión del Sr. Arzobispo de Manila de allegar fondos con que poder dedicar un homenaje de gratitud y admiración al marqués de Estella por los beneficios reportados al país.

Es una idea que parece tan justa como patriótica; y teniendo en cuenta los escasos recursos con que cuenta la Provincia, dispone que todos los religiosos contribuyan "con un día de haber de lo que corresponda por concepto de estipendios) ${ }^{16}$.

Al marqués de Estella le sustituyó el general D. Basilio Agustín. Este, "desconocedor por completo del país que había de gobernar), tampoco tuvo habilidad suficiente para asesorarse de las personas sensatas.

Antes, por el contrario, rodeado de los elementos nada sanos, que habían recorrido con su antecesor el camino de imprudencias ya descrito, no supo ponerse a la altura de las circunstancias, comenzando el derrotero de debilidades que la historia se encargará de señalar con caracteres de enérgica protesta ${ }^{17}$.

De entre los torpes y despistados gobernadores, ¿ podremos sal. var siquiera al general Polavieja? D. Camilo García Polavieja, uno de

\footnotetext{
15. ARCHIVO AGUSTINOS de VALLADOLID, n.o 3862 .

16. Ib. n.० 3946 .

17. J. D. DURAN, Episodios..., 22.
} 
los generales "del desastre» $\mathrm{y}$, sin embargo, el símbolo de una esperanza española, ya en 1879 , refiriéndose al caso de Cuba había escrito lo siguiente: "En vez de querer impedir a todo trance la independencia de Cuba, que empeño vano sería, debemos prepararnos para ella»... "Es creencia mía que el pueblo que descubrió, conquistó y colonizó la isla de Cuba, está obligado por su propia honra, por los destinos de su raza y por sus propios intereses a dejar tras de sí una fuerte nacionalidad en Cuba, para que ésta, con la República Mejicana, fije los límites de la raza sajona, conteniéndola en su marcha invasora) ${ }^{18}$.

El ilustre soldado llegaba a Manila antes que los dos gobernadores últimamente citados, en diciembre de 1896 , exactamente el año de la insurrección. Llegaba precedido de una justísima y reputada fama. Militar victorioso en cien combates dentro del suelo patrio y en tierras extrañas, evidenció las más altas dotes militares. Al tomar posesión de su cargo, Polavieja se dirigió a todos los habitantes del Archipiélago con hermosas y elocuentes palabras que reproduce Sastrón. El mismo tono fue utilizado en el manifiesto a los soldados del Ejército y Armada. «El mundo entero - les decía entre otras cosasproclama vuestras virtudes militares. El valor, la sobriedad, la abnegación y la disciplina son cualidades reconocidas universalmente en el soldado español) ${ }^{19}$.

Pero, por desgracia, no duró mucho tiempo en su cargo tan prestigioso general. Al atender demasiado y heroicamente a la salud patria, había descuidado la suya propia. Su prolongada estancia en los climas cálidos le hirió, como dice el mejor narrador de los episodios de la insurrección filipina, «la entraña que más fijamente hiere el constitutivo de los europeos: el hígado', y aquel bravo militar tuvo que regresar a la Península.

Aun cuando más adelante nos será forzoso volver sobre el mismo asunto, no podemos pasar en silencio, por lo que atañe al general Polavieja , el célebre "caso Rizal), que tanto dice en favor de las tolerancias y de las equivocaciones sufridas por nuestros gobernadores en Filipinas.

\footnotetext{
18. M. FERNANDEZ ALMAGRO, En torno al 98, 52-58.

19. M. SASTRON, o.c. 158-160.
} 
"Aquel ente vulgar y sin legítimo brillo", como fue calificado por el autor del "Katipunan», no dejó de representar un importante papel, debido a las consideraciones que el gobierno y las autoridades superiores le concedieran.

Ya veremos lo que esto significó para la revolución filipina. Aquí solamente y ocasionalmente diremos que Rizal supo aprovechar la falta de visión de nuestros gobernantes para presentarse como el apóstol de los filibusteros y redentor de la raza indígena, maltratada y esclavizada.

Lo curioso es que, al principio, solamente siguieron al cabecilla "cuatro abogadillos adocenados y torpes, algunos caballeros con título académico y un montón de indios, sacados del pueblo de Calambre, de donde era natural el líder» ${ }^{20}$. El primero en caer en las redes de la astucia filipina fue el general Eulogio Despujols, Gobernador General del Archipiélago, al que convenció de que sus libros y escritos nada decían contra la madre Patria. Con lo cual, pudo volver de su relativo destierro ${ }^{21}$ si bien, convicto y confeso de filibusterismo, fuera condenado y deportado a Dapitán.

Pero el golpe de mano de su astucia lo dio cuando, en plena guerra de Cuba, pidió de las autoridades que se le concediera pasar a las Antillas en calidad de médico y para prestar sus servicios al ejército español. Ahora es el general Blanco quien cae en el lazo y le permite volver a Manila.

Finalmente, si no fue acertada la conducta seguida con el cabecilla por parte de los dos personajes citados, menos acertada creemos, fue la orden de ejecución dada por el general Polavieja. Faltaba un mártir, una víctima de la revolución, y los insurrectos ya la tenían desde el 26 de diciembre de 1896 . La orden de ejecución se cumpliría el día 30 del mismo mes a las 7 de la mañana ${ }^{22}$.

20. J. M. CASTILLO, EI Katipunan, 279.

21. Rizal estaba confinado en Hong-Kong cuando escribió una carta-súplica al general Despujols para que le permitiera ir a Manila y poder abrazar asi a su familia. En la maleta de su equipaje le hallaron unas proclamas filibusteras que pasaron al despacho del gobernador, el cual, no obstante, accedió a la petición del líder que pedía el indulto de su padre, deportado a la sazón por los sucesos revolucionarios de Calambre.

22. Los detalles del consejo de guerra y de la condena del cabecilla intelectual filipino, en M. SASTRON, o. c. 77-183. 
Para terminar este capítulo de gobiernos y de gobernadores, sólo nos resta decir que no sería el general Agustín el que habría de llevar a cabo la dolorosa entrega de la plaza de Manila: el momento de arriar la bandera española del balcón del Ayuntamiento de la Capital de Legazpi y Salcedo estaba reservado para el Capitán General Jaúdenes ${ }^{23}$.

La desgracia para España se consumaría el ro de diciembre de ı 898 en el Congreso de Paris, ratificada el to de abril de 1899.

(Continuará)

TEÓfILO APARICIO

23. El texto oficial y literario del documento relativo a la capitulación de Manila puede leerse en el citado Sastrón, págs. 505-507.

En el Colegio Seminario de PP. Agustinos-Filipinos de Valladolid se conserva la mesa en que se firmó la capitulación de Manila; asi como también la espada que el General Jáudenes entregó a los religiosos Agustinos del convento de Manila, la cual se custodia alli como un valioso recuerdo, tan preciado como la bandera española que se llevaron los americanos y que tanto tiempo estuvo izada en el Ayuntamiento de aquella capital. 